\title{
Emergency Management of Hypertension in Children
}

\author{
Dinesh Singh, ${ }^{1}$ Olugbenga Akingbola, ${ }^{1}$ Ihor Yosypiv, ${ }^{2}$ and Samir El-Dahr ${ }^{2}$ \\ ${ }^{1}$ Division of Pediatric Critical Care, Department of Pediatrics, Tulane University Health Sciences Center, 1430 Tulane Avenue, \\ SL-37, New Orleans, LA 70112, USA \\ ${ }^{2}$ Division of Pediatric Nephrology, Department of Pediatrics, Tulane University Health Sciences Center, New Orleans, \\ LA 70112, USA
}

Correspondence should be addressed to Dinesh Singh, thakurdinesh@yahoo.com

Received 29 August 2011; Revised 13 December 2011; Accepted 12 January 2012

Academic Editor: Alberto Edefonti

Copyright (c) 2012 Dinesh Singh et al. This is an open access article distributed under the Creative Commons Attribution License, which permits unrestricted use, distribution, and reproduction in any medium, provided the original work is properly cited.

Systemic arterial hypertension in children has traditionally been thought to be secondary in origin. Increased incidence of risk factors like obesity, sedentary life-styles, and faulty dietary habits has led to increased prevalence of the primary arterial hypertension $(\mathrm{PAH})$, particularly in adolescent age children. PAH has become a global epidemic worldwide imposing huge economic constraint on health care. Sudden acute increase in systolic and diastolic blood pressure can lead to hypertensive crisis. While it generally pertains to secondary hypertension, occurrence of hypertensive crisis in PAH is however rare in children. Hypertensive crisis has been further subclassified depending on presence or absence of end-organ damage into hypertensive emergency or urgency. Both hypertensive emergencies and urgencies are known to cause significant morbidity and mortality. Increasing awareness among the physicians, targeted at investigation of the pathophysiology of hypertension and its complications, better screening methods, generation, and implementation of novel treatment modalities will impact overall outcomes. In this paper, we discuss the etiology, pathogenesis, and management of hypertensive crisis in children. An extensive database search using keywords was done to obtain the information.

\section{Definitions and Epidemiology}

Primary arterial hypertension is a global epidemic affecting predominantly adult population [1]. Although secondary etiologies of hypertension predominate in children, the prevalence of primary arterial hypertension has been increasing at an alarming rate particularly in adolescents and older children [2]. Recent survey conducted by the National Health and Nutrition Examination Survey (NHANES) in 8-17year-old children showed a prevalence of prehypertension and hypertension of about $10 \%$ and $4 \%$, respectively, with a higher incidence in African American and Mexican Americans [3]. Increase in the prevalence of hypertension has paralleled the increased prevalence of childhood obesity [4]. Childhood obesity has increased by more than three times in the past three decades [5]. The Fourth Report on the Diagnosis, Evaluation, and Treatment of High Blood Pressure in Children and Adolescents classified pediatric hypertension into various stages [6] (Table 1). In one study the incidence of stage 1 and 2 hypertension was reported to be $2.6 \%$ and $0.6 \%$, respectively, in adolescent students [7]. The Joint National Committee on Detection, Evaluation, and Treatment of Hypertension, JNC7, has labeled acute severe elevation of blood pressure above 180/120 $\mathrm{mmHg}$ (about $20 \mathrm{mmHg}$ above the Stage II hypertension) as "Hypertensive Crisis" in adults [8]. It is further subclassified based on presence of target organ abnormalities like seizures, intracranial hemorrhage, Posterior reversible encephalopathy syndrome (PRES), focal neurological deficit, congestive cardiac failure, papilledema, retinal hemorrhages, and acute vision loss into Hypertensive Emergency and in the absence of target organ abnormalities as Hypertensive Urgency [8]. Unfortunately, no such clear definition has been proposed for Hypertensive Crises in children. Sequelae of hypertension emergencies like left ventricular failure, encephalopathy, aortic dissection, myocardial ischemia, acute renal insufficiency, and retinal damage are well known in adults [9]. However, target organ damage and adverse effects have also been demonstrated in older children and adolescents and are an evidence of long-term blood pressure elevation [10-17]. In addition, 
TABle 1: Definitions of normal and elevated blood pressure in children.

\begin{tabular}{|c|c|}
\hline Normal blood pressure & $\begin{array}{l}\text { Systolic and diastolic blood pressure } \\
\text { below } 90 \text { th centile }\end{array}$ \\
\hline Prehypertension & $\begin{array}{l}\text { Systolic or diastolic blood pressure } \\
\text { above the } 90 \text { th centile (or } 120 / 80 \\
\mathrm{mmHg} \text { ), but below the } 95 \text { th centile }\end{array}$ \\
\hline Stage I hypertension & $\begin{array}{l}\text { Systolic or diastolic blood pressure } \\
\text { higher than or equal to the 95th } \\
\text { centile, but lower than the 99th centile } \\
\text { plus } 5 \mathrm{~mm} \mathrm{Hg}\end{array}$ \\
\hline Stage II hypertension & $\begin{array}{l}\text { Systolic or diastolic BP higher than or } \\
\text { equal to the } 99 \text { th centile plus } 5 \mathrm{~mm} \mathrm{Hg}\end{array}$ \\
\hline
\end{tabular}

target organ damage has been reported even in neonates and pediatric patients with prehypertension and white coat hypertension, implying that any age and any level of hypertension could result in long-term consequences. About $1 \%$ of all adults with a diagnosis of hypertension develop Hypertensive crisis, of which $76 \%$ are hypertensive urgencies and $24 \%$ are hypertensive emergencies [18]. Similar data in children is not available. In addition, although the prevalence of the primary hypertension has increased over the past three decades, the incidence of hypertensive crisis is very uncommon in pediatric patients with primary hypertension and its occurrence is more common in pediatric patients with secondary hypertension. Terminologies like Accelerated Hypertension and Malignant Hypertension are obsolete and should not be used.

Etiology. In adults, majority of the cases of hypertensive crises are due to nonadherence to prescribed medication, drug overdose, sudden withdrawal of antihypertensive medications, and so forth [19-22]. In comparison, majority of pediatric hypertensive crises are renal in origin [23]. Interestingly, etiologies also differ according to the patient's age, onset (acute versus chronic), and duration (intermittent/episodic or persistent). For example, conditions like coarctation of aorta, renal vein, or artery thrombosis predominate in neonates. However, renal parenchymal diseases, pregnancy, endocrine conditions, autoimmune diseases, medications, drugs, and alcohol are important etiologies in older children and adolescents. Conditions like pheochromocytoma can present with episodic or sustained hypertension whereas chronic glomerulonephritis has persistent/sustained hypertension (Table 2).

Pathophysiology and Pathogenesis. Blood pressure is a product of cardiac output and peripheral vascular resistance (PVR). Cardiac output is a product of heart rate and stroke volume. In turn, stroke volume is determined by preload, contractility, and after-load/PVR [24]. Figure 1 outlines the various factors that determine the arterial blood pressure (adapted with permission from [25]). Any factor which enhances the heart rate and determinants of stroke volume would result in hypertension. The pathogenesis of hypertensive crisis is multifactorial and much of the supportive
TABLE 2: Causes of hypertension in children.

\begin{tabular}{|c|c|}
\hline \multirow{12}{*}{ Renal } & Congenital dysplastic kidneys \\
\hline & Multicystic kidney disease \\
\hline & Polycystic kidney disease \\
\hline & Hydronephrosis \\
\hline & Renal artery stenosis \\
\hline & Renal vein thrombosis \\
\hline & Glomerulonephritis \\
\hline & $\begin{array}{l}\text { Acute tubular necrosis } \\
\text { Hemolytic-Uremic svndrome }\end{array}$ \\
\hline & Obstructive uropathy \\
\hline & Wilms tumor \\
\hline & Diabetic nephropathy \\
\hline & Pyelonephritis \\
\hline \multirow{3}{*}{ Cardiovascular } & Coarctation of aorta \\
\hline & Takayasu's arteritis \\
\hline & Moyamoya disease \\
\hline \multirow{5}{*}{ Endocrine } & Cushing's syndrome \\
\hline & Hyperthyroidism \\
\hline & Hyperparathyroidism \\
\hline & $\begin{array}{l}\text { Congenital adrenal } \\
\text { hyperplasia }\end{array}$ \\
\hline & Pheochromocytoma \\
\hline \multirow{13}{*}{$\begin{array}{l}\text { Medications, } \\
\text { drugs, and } \\
\text { toxins/poisons }\end{array}$} & Corticosteroids \\
\hline & Tacrolimus \\
\hline & Cyclosporine \\
\hline & Erythropoietin \\
\hline & Amphetamines \\
\hline & Oral contraceptives \\
\hline & Anabolic steroids \\
\hline & Phencyclidine \\
\hline & Vitamin D intoxication \\
\hline & Cocaine \\
\hline & Alcohol \\
\hline & Smoking \\
\hline & $\begin{array}{l}\text { Lead, thallium, mercury } \\
\text { toxicity }\end{array}$ \\
\hline \multirow{6}{*}{$\begin{array}{l}\text { Central nervous } \\
\text { system }\end{array}$} & Brain tumors \\
\hline & Intracranial hemorrhage \\
\hline & Raised ICP \\
\hline & Autonomic dysfunction \\
\hline & Neuroblastoma \\
\hline & Encephalitis \\
\hline \multirow{6}{*}{ Autoimmune } & Systemic lupus erythematosus \\
\hline & Polyarteritis nodosa \\
\hline & Rheumatoid arthritis \\
\hline & Goodpasture's disease \\
\hline & Wegener's Disease \\
\hline & $\begin{array}{l}\text { Mixed connective tissue } \\
\text { disorders }\end{array}$ \\
\hline
\end{tabular}


TABle 2: Continued.

\begin{tabular}{ll}
\hline & Obesity \\
Pregnancy & IUGR \\
Umbilical artery \\
catheterization \\
Hiscellaneous & Hypercalcemia \\
& Pain \\
& Drug withdrawal (opiates, \\
clonidine, beta-blocker) \\
\hline Gordon syndrome \\
Liddle's syndrome \\
Turner's syndrome \\
William's Syndrome \\
Friedreich's ataxia \\
Von Hippel-Lindau syndrome \\
Tuberous sclerosis complex \\
Neurofibromatosis \\
Multiple endocrine neoplasia \\
\hline
\end{tabular}

data is based on both animal and human adult studies. The factors that have been implicated in the pathogenesis include elevated blood pressure, fluid overload, sympathetic overactivity, renin-angiotensin-aldosterone system activation, oxidative stress, endothelial dysfunction, and inflammation. There is a complex interaction between all these factors and all or some factors occurring simultaneously may be involved in the pathogenesis of hypertensive crisis.

\section{Elevated Blood Pressure}

Complex interactions between renal, humoral, neural, and cardiovascular systems are involved in the maintenance of normal perfusion pressures to target organs during fluctuations of blood pressures [24]. Any disturbance in the autoregulatory mechanisms results in mechanical stress resulting in vascular injury and endothelial damage. Endothelial damage thus initiates a cascade of proproliferative, prothrombotic, and proinflammatory reactions, in addition to release of vasoactive peptides. These cascades of events eventually result in fibrinoid necrosis and tissue ischemia. This culminates into a vicious cycle of tissue ischemia potentiating the blood pressure due to release of vasoactive peptides, sympathetic overactivity, and fluid retention leading to further endothelial damage and inflammation which in turn again worsen the tissue ischemia $[26,27]$.

\section{Renin-Angiotensin-Aldosterone System (RAAS)}

RAAS plays an important role in the regulation of blood pressure and during hypertensive crisis [28]. The enzyme renin acts on angiotensinogen (AGT) to generate angiotensin I (Ang I). Ang I is further converted to angiotensin II (Ang II) by angiotensin converting enzyme (ACE). Ang II exerts its effects by binding to two major types of receptors- $-\mathrm{AT}_{1} \mathrm{R}$ and $\mathrm{AT}_{2} \mathrm{R}$ [29]. Functions like vasoconstriction, cellular proliferation, cellular hypertrophy, fibrosis, atherosclerosis, antinatriuresis, and release of aldosterone, endothelin, norepinephrine, and vasopressin are initiated by binding of Ang II to $\mathrm{AT}_{1} \mathrm{R}$. In addition, Ang II induces mitochondrial dysfunction via a protein kinase C-dependent pathway by activating the endothelial cell NADPH oxidase and formation of peroxynitrite [30]. A recent study demonstrated that Ang II stimulates increased IL-6 production both in vivo and in vitro. In addition to its role in hypertension, increased IL-6 may play an important pathogenic role in CKD by Ang II-mediated induction of multiple fibrotic genes and ET-1 production leading to renal injury and fibrosis [31]. In addition, recent identification (Pro) Renin receptors and functionally active Ang II-derived peptides like Ang 1-7 have been shown to play pathological role in causing hypertension [32].

\section{Inflammation}

Various inflammatory cytokines and chemokines have been implicated in the pathogenesis of hypertension. Ang II has been shown to be proinflammatory and profibrotic by inducing and activating various inflammatory pathways and upregulating cytokines, chemokines, and NFKB. The pivotal role of various T-cell subsets and macrophages in the regulation of blood pressure and target organ damage has been demonstrated in recent studies [33-38]. Amelioration of the target organ damage by immune-suppressant treatment further confirms involvement of immune mediators in the pathogenesis of hypertension. Ang II also facilitates recruitment of leukocytes through the endothelium by induction of ICAM-1 and VCAM-1 $[39,40]$. T lymphocytes CD4 (+) and, to a lesser extent, CD8 (+) have been demonstrated to mediate the accelerated microvascular thrombosis associated with Ang II-induced hypertension [41]. Although the exact mechanism is unclear, it is thought to be secondary to complex interaction between platelets and cytokines resulting in activation of coagulation cascade. In addition, the presence of NADPH oxidase-derived reactive oxygen species also facilitates prothrombotic action of Ang II [41]. Recent study also demonstrated immunosuppressive properties of regulatory $\mathrm{T}$ cells (Treg) when adaptive transfer of isolated Treg cells into Ang II-infused mice resulted in amelioration of cardiac damage [42].

\section{Oxidative Stress and Endothelial Dysfunction.}

Nitric oxide (NO) is synthesized by endothelial nitric oxide synthase (eNOS) in the vascular endothelium from its precursor molecule L-arginine. NO in the presence of soluble guanylate cyclase $(\mathrm{sGC})$ results in increased intracellular levels of cyclic Guanosine monophosphate (cGMP). Elevated 
cGMP causes decrease in intracellular calcium ion levels leading to decreased vascular tone. Oxidative stress may play a causal role in the development of hypertension by altering the vascular tone either by oxidative modification of proteins and nucleic acids or by decreasing the bioavailability of nitric oxide. Superoxide anions generated by various enzymes such as NADPH oxidase, xanthine oxidase, and enzymes involved in mitochondrial respiratory chain may directly inactivate $\mathrm{NO}$ and inhibit sGC. Increased angiotensin II levels facilitate further generation of superoxide anions by stimulating these enzymes. In addition, superoxide anions lead to uncoupling of eNOS by oxidating the BH4 (tetrahydrobiopterin). BH4 is an essential cofactor necessary in generation of NO by eNOS enzyme. Uncoupling of eNOS also facilitates further generation of superoxide anions. These superoxide anions cause increased vascular cell proliferation and migration, apoptosis, inflammation, extracellular matrix alterations, and endothelial dysfunction [43-46].

\section{Central Nervous System}

The role of central nervous system in the regulation of blood pressure via modulation of sympathetic and parasympathetic nervous system is well known. However, recent studies suggest that increased sodium intake results in increase in endogenous ouabain (EO) levels in the paraventricular and supraoptic nuclei and at the circumventricular organs such as subfornical organ. This induces an acute but transient Ang-II- mediated increase in peripheral sympathetic nervous system resulting in elevation in blood pressures. Experiments conducted in rats reveal complex interactions involving sodium ions, epithelial sodium channels (ENaCs), RAAS, and EO in the brain which activate sympathetic nervous system. Thus, a brain $\mathrm{Na}^{+}$-ENaC-RAAS-EO pathway and a neuromodulatory pathway involving Aldosterone-EO-Ang II have been proposed in explaining the mechanism of action of hypertension. Further research and understanding of these novel mechanisms will help in newer antihypertensive therapies [47].

In addition, genetic mutations and polymorphisms [48], and insulin resistance [49], and abnormalities involving the sodium transport mechanisms like $\mathrm{Na}^{+} / \mathrm{H}^{+}$exchanger, $\mathrm{Na}^{+} / \mathrm{K}^{+} / 2 \mathrm{Cl}^{-}$cotransporter, $\mathrm{Na}^{+} \mathrm{Cl}^{-}$cotransporter, $\mathrm{Na}^{+} / \mathrm{K}^{+}$ ATPase, and sodium-phosphate cotransporter $[50,51]$ have also been implicated in the pathogenesis of hypertension. A possible mechanism of hypertensive crisis is shown in Figure 2.

6.1. Clinical Features and Target-Organ Damage. Clinical presentation varies depending upon age, the target organ involved, and etiology. Neonates may present with apnea, cyanosis, irritability, and poor feeding [52].In addition, clinical features may reflect specific etiologies like endocrine diseases, autoimmune conditions, pregnancy, and drug abuse. Older children with long-term hypertension or acute exacerbation of chronic hypertension or sudden severe elevation of blood pressure may present with symptoms related to end organ abnormalities involving the heart, eye, kidney, and brain [53].
6.2. Cardiovascular Manifestations. Depending on the duration and acuity of the symptoms, the cardiac involvement can be in the form of left ventricular hypertrophy (LVH), left ventricular failure, or left ventricular ischemia $[54,55]$. Although left ventricular hypertrophy has traditionally been defined in pediatric population as left ventricular mass index (LVMI) greater than $38.6 \mathrm{~g} / \mathrm{m}^{2.7}$ and has been recommended in the fourth report, a recent study has demonstrated that LVMI varies significantly in children particularly those $<9$ years of age. The study which was performed in 2,273 nonobese, healthy children demonstrated that in children aged $>9$ years the 50th percentile values of LVMI ranged from $27 \mathrm{~g} / \mathrm{m}^{2.7}$ (girls) to $32 \mathrm{~g} / \mathrm{m}^{2.7}$ (boys) and varied little with age. The 95 th percentile values of LVMI in the $>9$ years age group ranged from $40 \mathrm{~g} / \mathrm{m}^{2.7}$ (girls) to $45 \mathrm{~g} / \mathrm{m}^{2.7}$ (boys). The authors concluded that values $>40 \mathrm{~g} / \mathrm{m}^{2.7}$ in girls and $>45 \mathrm{~g} / \mathrm{m}^{2.7}$ in boys should be considered abnormal. In contrast, the 50th percentile values of LVMI in children $<9$ years age group varied significantly from $56.44 \mathrm{~g} / \mathrm{m}^{2.7}$ (boys) and $55.38 \mathrm{~g} / \mathrm{m}^{2.7}$ (girls) in infants less than 6 months of age to $31.79 \mathrm{~g} / \mathrm{m}^{2.7}$ (boys) and $29.71 \mathrm{~g} / \mathrm{m}^{2.7}$ (girls) in children less than 8years of age. Similarly, the 95th percentile values of LVMI in the $<9$ years age group varied from $80.1 \mathrm{~g} / \mathrm{m}^{2.7}$ (boys) and $85.6 \mathrm{~g} / \mathrm{m}^{2.7}$ (girls) in infants less than 6 months of age to $44.6 \mathrm{~g} / \mathrm{m}^{2.7}$ (boys) and $43.5 \mathrm{~g} / \mathrm{m}^{2.7}$ (girls) in children less than 8 years of age (Table 3 ). This study provides normal percentile values for young children and emphasizes the need for age-appropriate LVMI cut points and use of appropriate percentile curves particularly in children $<9$ years of age [56]. The LVH is common in children with hypertension with an incidence of $41.1 \%$ particularly in children with high Body-Mass index (BMI) and in Hispanic population [57]. Left ventricular failure can lead to symptoms such as increased work of breathing, shortness of breath, chest pain, palpitations, decreased urine output, and poor appetite. Sudden acute increase in blood pressure may precipitate left ventricular failure in any pediatric age group but is more commonly reported in neonates [58-60]. Carotid intima media thickness (CIMT), measured by Bmode ultrasound at end diastole, has emerged as a surrogate marker of early atherosclerotic changes and is predictive of adult cardiovascular structural damage. Indeed, increasing number of studies in children with hypertension, dyslipidemia, diabetes, and obesity have shown an increased CIMT. However, a recent study showed that nonobese children with primary hypertension had increased CIMT compared with BMI-matched controls. Although obesity may play a significant role in vascular changes, this study provides strong and interesting evidence that CIMT may be increased in nonobese children with primary hypertension. The major drawback of this surrogate marker is that the reference values are not available for children younger than 10 years and further studies are needed to determine reference values of CIMT in this age group [61-63].

6.3. Neurological Manifestations. Loss of cerebral autoregulation leading to disruption of the blood brain barrier and endothelial dysfunction results in imbalance in oxygen delivery, edema formation, and microhemorrhages [64]. 


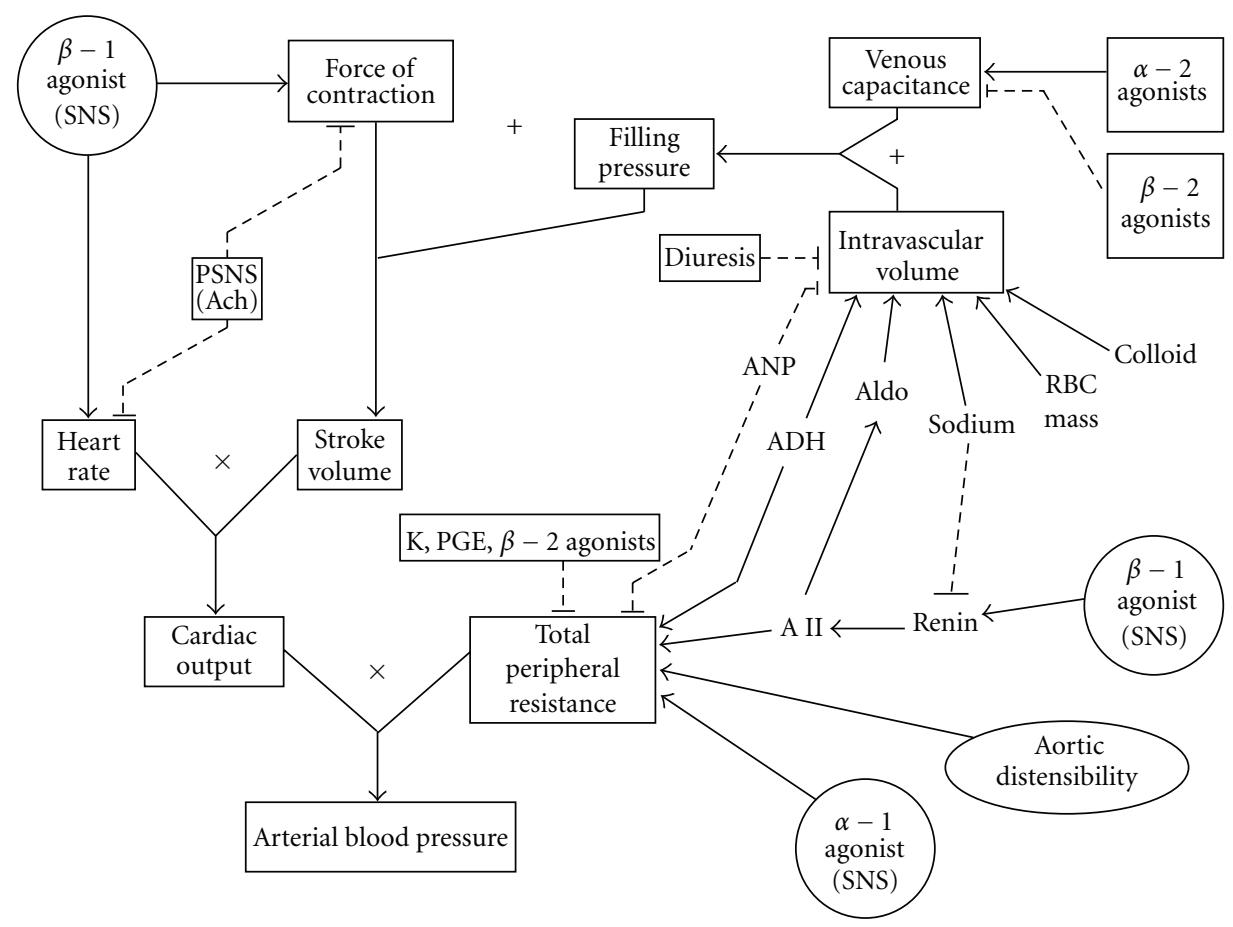

FigURE 1: Factors that determine the arterial blood pressure (adapted with permission from [25]).

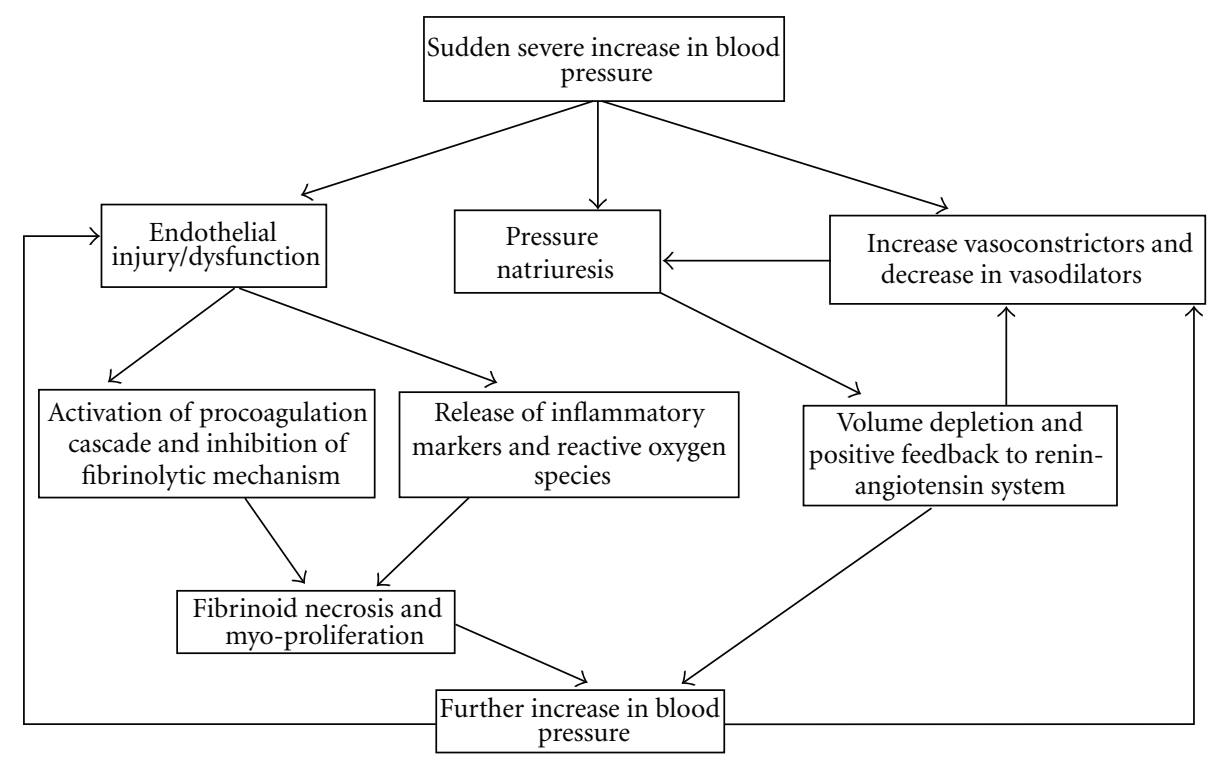

FIGURE 2: Mechanism of hypertensive crisis.

TABLE 3: Age-specific reference values of the LVMI in boys and girls Adapted from [56].

\begin{tabular}{lccc}
\hline Age & Sex & LVMI $(50$ th percentile) & LVMI (95th percentile) \\
\hline \multirow{2}{*}{$>9$ years } & Boys & $32.0 \mathrm{~g} / \mathrm{m}^{2.7}$ & $45.0 \mathrm{~g} / \mathrm{m}^{2.7}$ \\
& Girls & $27.0 \mathrm{~g} / \mathrm{m}^{2.7}$ & $40.0 \mathrm{~g} / \mathrm{m}^{2.7}$ \\
\hline \multirow{2}{*}{$<8$ years } & Boys & $31.79 \mathrm{~g} / \mathrm{m}^{2.7}$ & $44.6 \mathrm{~g} / \mathrm{m}^{2.7}$ \\
& Girls & $29.71 \mathrm{~g} / \mathrm{m}^{2.7}$ & $43.5 \mathrm{~g} / \mathrm{m}^{2.7}$ \\
\hline \multirow{2}{*}{$<6$ months } & Boys & $56.44 \mathrm{~g} / \mathrm{m}^{2.7}$ & $80.1 \mathrm{~g} / \mathrm{m}^{2.7}$ \\
& Girls & $55.38 \mathrm{~g} / \mathrm{m}^{2.7}$ & $85.6 \mathrm{~g} / \mathrm{m}^{2.7}$ \\
\hline
\end{tabular}


These changes may lead to seizures, altered mental status, PRES, vomiting, signs of raised intracranial pressure, focal neurological deficits, and headache. Headache is the most common symptom [65-69]. In one study seizures occurred in $25 \%$ of children, encephalopathy in $25 \%$, facial palsy in $12 \%$, and hemiplegia in $8 \%$ [18]. Posterior reversible encephalopathy syndrome has been reported to predominantly affect the occipitoparietal white matter with occasional spread to basal ganglia, cerebellum, and brainstem. Various etiologies like post-chemotherapy, posttransplant, postinfectious, autoimmune conditions, and posthypertensive crisis have been known to cause PRES. Clinical features include headache, altered mental status, nausea, vomiting, seizures, cortical blindness, and focal neurological deficits. Magnetic Resonance Imaging shows bilateral, symmetrical, involvement of white matter in occipitoparietal regions which appear as hyperintense lesions on T2-weighted images and hypointense or isointense lesions on Diffusion-Weighted Images. PRES is a completely reversible condition with occasional reports of neurological deficits [70-72].

6.4. Renal Manifestations. Hematuria, flank pain, and oliguria would indicate renal involvement. The most common etiology leading to hypertension in children is renal disease but hypertension itself can result in renal injury and failure secondary to loss of autoregulation of renal blood flow. But the data exploring the impact of hypertension on the renal function and structural injury in pediatric population is limited. Histologically fibrinoid necrosis with thrombosis involving the intrarenal arteries has been demonstrated in adult studies which result in clinical presentation consistent with microangiopathic hemolytic anemia $[73,74]$. A recent study, however, has demonstrated increased microalbuminuria and decreased glomerular filteration rate in prehypertensive children particularly with high blood pressure load [75]. In addition, another study demonstrated a reduction in microalbuminuria and LVH when hypertension was controlled with ACE inhibitors [76]. These findings suggest that renal dysfunction and structural injury may occur early even in pediatric population with hypertension and continue into adult life and studies are needed to further elucidate these findings.

6.5. Ophthalmological Manifestations. Retinal bleeds, papilledema, loss of visual acuity, acute ischemic optic neuropathy, and cortical blindness have been reported secondary to hypertensive crisis [77]. Loss of vision can be serious and permanent. Traditionally hypertensive retinopathy assessed by direct fundoscopy has been described based on Keith-Wagner-Barkar's classification (1939) which was subsequently modified by Scheie (1953) $[78,79]$. The major drawback of these classifications is that direct fundoscopic examination is limited by physician's experience and high inter- and intraobserver variability. More recently Wong and Mitchell (2004) (Table 4) proposed a new classification which stratified cardiovascular risks associated with different grades of hypertensive retinopathy in adults [80]. The data regarding the prevalence of hypertensive retinopathy in general pediatric population is largely unknown. However, in two studies the prevalence of hypertensive retinopathy in children with hypertension varied from $8.9 \%$ (assessed by direct fundoscopy) to $50 \%$ (assessed by retinal photographs) [13, 81]. Majority of the children in both studies had mild retinopathy and none had higher-grade retinopathy. In addition, evidence of grade III and grade IV hypertensive retinopathy was lacking in $32 \%$ of adults with hypertensive encephalopathy [82]. Although many studies involving the risk stratification and prognostic importance based on the retinopathy grades are available in adults, no such data exists in pediatric population. In general, moderate-to-severe grades of retinopathy are relatively rare in children and further studies are needed to elucidate the importance of mild retinopathy and long-term prognosis. But newer techniques like digital imaging and computer analysis of the early retinal changes and newer grading systems will further help in risk stratification and disease progression [83].

\section{Clinical Assessment}

Clinical assessment begins with obtaining relevant present, past medical history. Potential risk factors include history of low birth weight, intrauterine growth retardation, prematurity, oligo or polyhydramnios, umbilical artery catheterization, recurrent urinary tract infections, weak stream of the urine in male child, hematuria, flank pain, polyuria, failure to thrive, joint pains, skin rashes, headaches, visual disturbances, chest pain, palpitations, and poly or oliguria. Family history of diabetes, hypertension, obesity, hypercholesteremia, early strokes, coronary artery diseases, sudden cardiac deaths, malignancies, autoimmune conditions, or hereditary conditions involving the kidneys, liver, and brain should be assessed. A detailed endocrine-related history should also be obtained. Medication history involving steroids, antihypertensives, tacrolimus, cyclosporine, oral contraceptives, and dietary and life-style history regarding smoking, alcohol, and drug abuse should be elucidated. In addition in teenage adolescent girls, pregnancy-related symptoms should be elicited. In obese children, history of sleep apnea and daytime somnolence should be obtained.

Physical examination should involve general examination to look for edema, skin rashes, neurocutaneous markers, cyanosis, elfin facies, webbing of neck, hirsutism, cushingoid features, thyroid enlargement, proptosis, and so forth. Heart rate, respiratory rate, and four-extremity blood pressure preferably both in lying and sitting position, peripheral pulses, height, weight, and BMI should be recorded. A detailed cardiovascular, respiratory, abdominal, and neurological examination should be performed to look for any evidence of coarctation, LVH, pulmonary edema, pleural, and pericardial effusions. In addition, examine for hepatosplenomegaly, intra-abdominal masses, ascites, and genitourinary abnormalities. Look for any evidence of spina bifida, hydrocephalus, signs of raised ICP, papilledema, focal neurological deficits, and cranial nerve palsies particularly 3rd and 7 th cranial nerves. 
TABLE 4: Wong and Mitchell's classification (adapted from [80]).

\begin{tabular}{|c|c|}
\hline Grading & Retinal signs \\
\hline Mild retinopathy & $\begin{array}{l}\text { Generalized arteriolar na } \\
\text { arteriolar narrowing, arte } \\
\text { nicking, opacity (copper } \\
\text { arteriolarwall, or a comb } \\
\text { these signs }\end{array}$ \\
\hline Moderate retinopathy & $\begin{array}{l}\text { Hemorrhage (blot, dot, o } \\
\text { shaped), microaneurysm } \\
\text { spot, hard exudates or a c } \\
\text { of these signs }\end{array}$ \\
\hline Severe retinopathy & $\begin{array}{l}\text { Moderate retinopathy pli } \\
\text { swelling \# }\end{array}$ \\
\hline $\begin{array}{l}\text { * A modest association is defined as } \\
\text { \#Anterior ischemic optic neuropathy }\end{array}$ & $\begin{array}{l}\text { tio of greater than } 1 \text { but less } t \\
\text { rized by unilateral swelling of }\end{array}$ \\
\hline \multicolumn{2}{|c|}{ TABLE 5: Initial workup for hypertension. } \\
\hline \multicolumn{2}{|l|}{ Complete blood count } \\
\hline \multicolumn{2}{|l|}{ Basic metabolic panel includ } \\
\hline \multicolumn{2}{|l|}{ Serum uric acid } \\
\hline \multicolumn{2}{|l|}{ Fasting lipid profile } \\
\hline \multicolumn{2}{|l|}{ Fasting blood glucose } \\
\hline \multicolumn{2}{|l|}{ Urine analysis/culture } \\
\hline \multicolumn{2}{|c|}{ Urine electrolytes, creatinine, protein } \\
\hline \multicolumn{2}{|l|}{ Chest X-ray } \\
\hline \multicolumn{2}{|l|}{ EKG and echocardiogram } \\
\hline Renal ultrasound with doppler & \\
\hline
\end{tabular}

\section{Laboratory Workup and Evaluation}

Successful management of the elevated blood pressure in children depends on the accurate diagnosis and evaluation of the etiology of hypertension. It is well known that the clinical spectrum of the etiology of hypertension is varied depending on the age of the child. Thus, it is vitally important that after a thorough history and physical examination, an extensive laboratory workup should be undertaken particularly in a young child who has extremely high pressure to rule out secondary causes of hypertension. In addition, workup should include tests and imaging studies to rule out endorgan damage. Some of the common initial workup and advanced investigatory studies based on the etiology have been outlined (Tables 5 and 6).

\section{Treatment}

Prompt recognition and treatment is of utmost importance to prevent target organ damage. Hypertensive emergency in children or adults is an indication for admission to intensive care unit for close monitoring and prompt initiation of appropriate intravenous antihypertensive therapy depending upon the etiology. Blood pressure should be preferably monitored continuously by invasive intra-arterial line or intermittently by noninvasive methods if intra-arterial line
TABLE 6: Further workup if needed depending upon the etiology.

\author{
TSH, Free T4. Free T3 \\ Serum cortisol \\ Serum aldosterone \\ Serum renin levels \\ HbAlC \\ 24 hr urinary catecholamine and metanephrine levels \\ (Pheochromocytoma) \\ Serum parathyroid hormone levels \\ Urine and serum toxicology screen \\ Urine pregnancy test \\ CT/MRI scan \\ DMSA/DTPA scan (renal scars) \\ MIBG scan (pheochromocytomas) \\ ANA/ESR/CRP/anti-dsDNA/anti-smith/rheumatoid \\ factor/pANCA/cANCA
}

cannot be obtained for any reason. Patient's cardiac, respiratory, and neurological status should be constantly monitored and prompt interventions implemented in case of any deterioration. Hypertensive urgency may be managed on regular pediatric unit and with oral antihypertensive medications. Moving the patient to intensive care unit may be considered in case of worsening of clinical condition (Figure 3). As per the Fourth Report on the Diagnosis, Evaluation, and Treatment of High Blood Pressure in Children and Adolescent, the primary aim of antihypertensive treatment is to reduce the blood pressure to $<95$ th percentile and to $<90$ th percentile in the presence of comorbid conditions like diabetes, cardiac, or renal disease. Furthermore, the mean arterial blood pressure should be lowered no more than $\leq 25 \%$ of the initial value in the first $1 \mathrm{hr}$ and a gradual reduction should be obtained over the next 24-48 hrs to normalize the blood pressure [6]. However, no clear guidelines exist about the rate of lowering the blood pressure in the presence of ischemic stroke.

Majority of the randomized clinical trials and data on anti-hypertensive medications are obtained from adult studies. Data regarding the safety, efficacy, and adverse events 


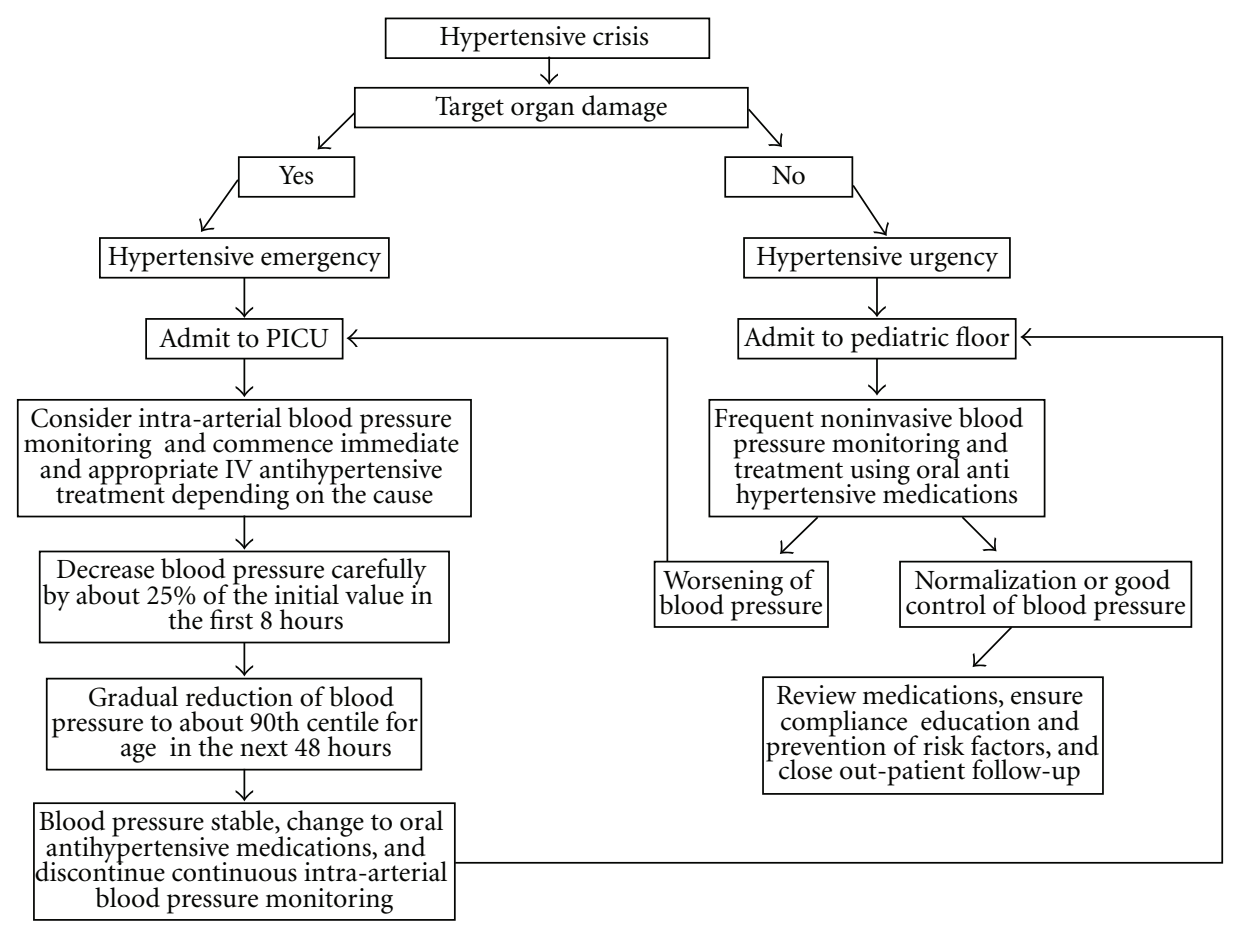

FIGURE 3: Proposed algorithm for the management of hypertensive crisis in children.

about most of the anti-hypertensive agents is not available in pediatric population and is either extrapolated from adult clinical trials or has been limited to expert opinions. Some of the intravenous antihypertensive medications used in the treatment of hypertensive emergencies include sodium nitroprusside, nicardipine, esmolol, hydralazine, labetalol, fenoldopam, and phentolamine. Some of the medications used in the treatment of hypertensive urgencies include enalapril, nifedipine, clonidine, minoxidil, and angiotensin II receptor blockers. In our institute depending upon the etiology and contraindications, we prefer to use sodium nitroprusside, nicardipine, and esmolol as our first, second, and third choices in the management of hypertensive emergency. In case of hypertensive urgencies, we prefer to use amlodipine, nifedipine, ACE inhibitors, angiotensin II receptor blockers, labetalol, or clonidine either alone or in combination. The details of the mechanisms of action and adverse effects are outlined in Table 7 . However, the results of a recent Cochrane review showed that there is no evidence demonstrating that antihypertensive drugs reduce mortality or morbidity in patients with hypertensive emergencies. The authors were unable to determine which drug or drug class is most effective in reducing mortality and morbidity. The authors concluded that RCTs are needed to assess different drug classes to determine initial and longer-term mortality and morbidity outcomes [84]. In the next section, we have summarized the management of hypertension crisis in some of the important pediatric conditions which we think may be more useful to the clinicians.

9.1. Hypertensive Crisis due to Medications or Drugs. Sudden cessation of opiates, benzodiazepines, and clonidine can also lead to withdrawal syndrome and present with hypertensive crisis. Reintroduction of medications causing the withdrawal followed by gradual weaning of the medications will result in resolution of hypertensive crisis in most cases. Cocaine toxicity is a well-known cause of hypertensive crisis particularly among adolescents. Mechanism of hypertensive crisis due to cocaine toxicity involves potentiation of catecholamine effects by inhibition of the presynaptic uptake of norepinephrine. Intravenous alpha-blocker like phentolamine is treatment of choice and beta-blockers may be added if needed later in the treatment [85-87]. Hypertensive crisis is also known to occur when medications like monoamine oxidase inhibitors interact with food containing tyramine and other medications like dextromethorphan, methylene blue, selective serotonin reuptake inhibitors, and linezolid. Hypertension due to MAOI interaction can be treated with either an alpha blocker or sodium nitroprusside [88-91]. Hypertensive crisis due to amphetamine toxicity is due to sympathomimetic and serotonergic effects of amphetamines. In addition to decontamination, cooling, sedation, intravenous alpha-blockers, or sodium nitroprusside is the treatment of choice $[92,93]$. Beta-blockers alone are absolutely contraindicated in all these toxidromes as they will worsen the hypertensive crisis due to unopposed action on alpha receptors.

9.2. Hypertensive Crisis due to Pheochromocytoma. Pheochromocytoma is rare tumor arising from chromaffin cells in the adrenal medulla and extra adrenal paraganglionic tissue in children. About $80 \%$ of the pheochromocytomas arise from adrenal medulla in children. Approximately $40 \%$ of 


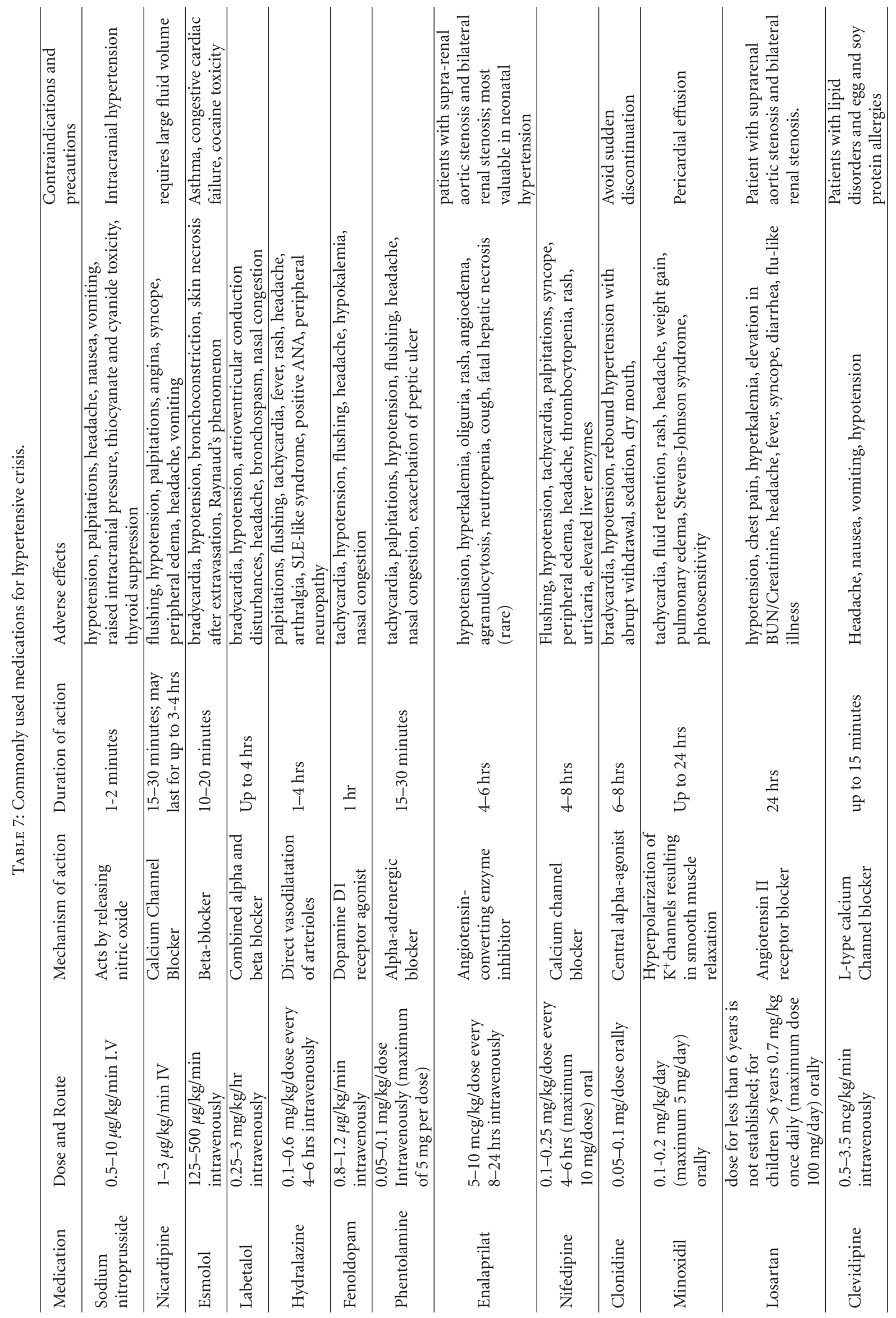


pheochromocytomas are associated with genetic mutations and about $19-38 \%$ are bilateral. About $1 \%$ of pediatric hypertensive patients have pheochromocytoma with a peak incidence at around 11 years. But it is more commonly diagnosed in adults with a peak incidence between 4th and 6th decade of life. Multiple endocrine neoplasia type 2, Von Hippel-Lindau syndrome, neurofibromatosis type 1 , and germline mutations of succinate dehydrogenase $(\mathrm{SDH})$ gene are some of the common causes of hereditary pheochromocytomas. Clinical presentation of pediatric pheochromocytoma is varied and ranges from asymptomatic to sustained hypertension in about $60-90 \%$. Paroxysmal hypertension is less common when compared to adults and its presence should raise a suspicion of pheochromocytoma. Children with dopamine secreting pheochromocytomas are usually normotensive. Symptoms such as headache, palpitations, sweating, vomiting, pallor, weight loss, polyuria, visual disturbances, anxiety, and attention deficit-hyperactivity are common presenting features in children. Quantification of plasma-free metanephrine and normetanephrine based on age-specific reference intervals and $24 \mathrm{hr}$ urinary-fractionated metanephrines preferably in supine position are most sensitive diagnostic tests for pheochromocytoma. After the biochemical confirmation of the diagnosis, tumor localization studies like magnetic resonance imaging (MRI), ${ }^{123}$ metaiodobenzylguanidine (MIBG) scintigraphy, and occasionally in rare cases studies like [111In]-Octreotide scintigraphy, [18F]-fluorodopamine, or [18F]-fluorodeoxyglucose positron emission tomography (FDG-PET) may be required. Surgery is the treatment of choice but good preoperative medical management of hypertension for at least 10-14 days is recommended. Adequate perioperative management of hypertension will result in decrease in postoperative complications. $\alpha^{2}$ blockade with noncompetitive $\alpha^{2}$-blocker like phenoxybenzamine is the medication of choice. For localized tumors laparoscopic cortical-sparing adrenalectomy is the preferred surgery in children. Treatment options for invasive and metastatic tumors include embolization, systemic therapy with ${ }^{131}$ MIBG, or chemotherapy [94-97].

\subsection{Hypertensive Crisis due to Renovascular Disease. Ren-} ovascular hypertension is an uncommon but important cause of correctable hypertension in children. $3-10 \%$ of the children evaluated for hypertension are found to have renovascular hypertension. Unlike atherosclerosis which is the most common cause of renovascular hypertension in adults, the most common etiology of the renovascular disease in children in Western countries is fibromuscular dysplasia. On the contrary, in developing Asian countries and South Africa, Takayasu's arteritis is the most common cause and is probably related to high incidence of tuberculosis in these countries. The other important etiologies of renovascular disease include syndromes like William's syndrome, Marfan's syndrome, Neurofibromatosis type 1, rubella syndrome, tuberous sclerosis, Klippel Trenaunay Weber syndrome, Linear sebaceous nevus syndrome and vasculitides like Kawasaki's disease, and Polyarteritis nodosa. In addition, extrinsic compression due to neuroblastoma, Wilms' tumor, and other tumors may lead to renal artery stenosis (RAS). Miscellaneous causes of RAS include irradiation, Crohn's disease, postrenal transplant, trauma and umbilical artery catherization. Children with the aforementioned conditions and hypertension should be meticulously evaluated for RAS. In addition, children with severe hypertension which is unresponsive or uncontrolled with multiple antihypertension medications or have renal arterial bruit, absent pulses, hypokalemia, elevated plasma renin activity, and unequal sizes of kidneys on ultrasound should also be investigated for RAS. RAS can be unilateral or bilateral, extrarenal, or intrarenal or both. Incidence of bilateral RAS is higher than unilateral RAS. It is important to know that renal artery bruit is an infrequent finding and may be absent in as many as 70\% of the patients with RAS. Although renal arteriography is the gold standard in the investigation of RAS, other less invasive methods like Doppler ultrasonography, magnetic resonance angiography, computerized tomographic angiography, captopril renography, and digital substraction angiography may be used initially. $\mathrm{CO}_{2}$ angiography has been advocated in patients with renal insufficiency to minimize contrastinduced renal injury but pediatric experience is limited. When the index of suspicion is high or when noninvasive methods have been tried, invasive techniques like renal arteriography and renal vein renin assays can be obtained to confirm the diagnosis. In the presence of unilateral disease a renal vein renin ratio of $>1.5$ between the affected and nonaffected kidney is considered significant. In absence of any difference in the ratios bilateral RAS may be suspected. Treatment depends upon the etiology, severity, and extent of the disease. In cases of RAS secondary to Takayasu's arteritis steroids, immunosuppressive therapy and antituberculous treatment are the mainstay. In general it is advisable to avoid diuretic therapy as it may increase plasma renin levels secondary to volume depletion. In children who have RAS which is amenable to surgical treatment, percutaneous transluminal renal angioplasty, stenting, segmental ethanol ablation, revascularization, and partial or total nephrectomy of the affected kidney are some of the options. In selected cases with diffuse and extensive bilateral intrarenal arterial lesions where surgical correction cannot be performed, a trial of angiotensin converting enzyme inhibitor or angiotensin receptor blocker has been advocated under close supervision by an experienced specialist in a tertiary hospital $[98,99]$.

9.4. Hypertension in Chronic Kidney Disease (CKD). Hypertension is a common occurrence in CKD increasing in severity with worsening in renal function. Both renoparenchymal diseases and tubulointerstitial diseases lead to renal scarring and reduction in nephron mass which results in activation of RAAS. The activation of RAAS leads to sodium and fluid retention and sympathetic hyperactivation contributing to hypertension. Volume overload is the most important factor leading to hypertension and hypertension-related morbidity and mortality in patients with CKD. In addition to the previous mechanism, several other factors like uremic toxins, increased circulating endogenous NOS inhibitors 
like asymmetric dimethylarginine, secondary hyperparathyroidism leading to hypercalcemia, and increased expression of endothelin A receptors have also been implicated in the pathogenesis of hypertension in CKD. Maintaining dry weight by strict volume control, dietary salt restriction, and frequent dialysis will markedly reduce the need for antihypertensive therapy. RAAS antagonist like ACE inhibitors and $\mathrm{ARB}$ are considered as first choice in the treatment of hypertension in this group of patients. RAAS antagonists not only lower transglomerular pressure and proteinuria but also suppress cytokines and chemokine release. These effects confer nephroprotection by reduction in glomerular hypertrophy and sclerosis and tubulointerstitial inflammation and fibrosis. In addition to RAAS antagonist, calcium channel blocker and beta-blockers are other therapeutic options $[100,101]$.

9.5. Hypertension in Microangiopathies. Thromboticmicroangiopathy (TMA) is characterized by Coomb's negative microangiopathic hemolytic anemia (MAHA), thrombocytopenia, and elevated lactate dehydrogenase levels. Histopathologically the lesion is characterized by endothelial injury and complete or partial obliteration of the arteriolar lumen by fibrin and platelet clots. Three types of TMA have been described-Glomerular TMA, Acute cortical necrosis and Arterial TMA - and have prognostic value. Acute cortical necrosis type of TMA is irreversible, glomerular TMA is partially reversible, and arterial TMA is predominantly seen in adults, is associated with recurrence or relapse and severe hypertension, and portends poor prognosis. Similar histopathological lesions have been described in conditions like Hemolytic-Uremic syndrome (HUS), Thrombotic Thrombocytopenic Purpura (TTP), and Hypertensive crisis of varied etiologies. Clinical features of these conditions can overlap and may be difficult to distinguish one from another. In general, thrombocytopenia is more severe in TMA induced by HUS/TTP compared to TMA secondary to hypertensive crisis. Von Willebrand factor cleaving protease enzyme (ADAMTS 13) deficiency is frequently associated with TTP or atypical HUS and normal in typical HUS. Renal involvement is common in all these conditions. Hypertensive crisis can be the end result of renal disease or can result in acute renal failure. HUS is one of the most common causes of acute renal failure in childhood and is characterized by a triad of Coomb's negative MAHA, thrombocytopenia, and acute renal failure. It has been classified as typical or D+ HUS (diarrhea associated) or atypical or DHUS (nondiarrhea associated). D+ HUS is more common, frequently secondary to infectious etiology like Shiga-toxin-producing enterohemorrhagic Escherichia coli, Shigella dysenteriae type 1, and Streptococcus pneumoniae, accounts for $90 \%$ of all cases, and carries more favorable prognosis when compared to the atypical HUS. Atypical HUS accounts for the remaining 10\% of cases and is secondary to genetic mutations in the proteins involved in the regulation of alternative complement pathway, or deficiency of Von Willebrand factor cleaving protease enzyme (ADAMTS 13), and vitamin
B12 metabolic defects. Renal failure is common in both typical and atypical HUS but the severity of the disease and hypertension is more pronounced in atypical HUS. Management of hypertension in these conditions includes avoidance of volume overload and maintenance of normal volume status, peritoneal dialysis or continuous renal replacement therapy, and etiology-specific therapies. In addition, in children with atypical HUS and TTP early plasmapheresis and plasma exchange has been used with variable results. Prolonged therapy with Eculizumab, a monoclonal antibody against C5 preventing the formation of membrane attack complex has been used in some atypical HUS cases. In patients with HUS secondary to vitamin B12 metabolic defects hydroxocobalamin therapy has been advocated [102-105].

9.6. Hypertension in Kidney Transplant Recipients. Hypertension is common in pediatric patients with renal transplant and occurs in up to $90 \%$ of the recipients. Hypertension in postrenal transplant recipients increases the risks of graft dysfunction and also cardiovascular morbidity and mortality. Some of the important factors responsible for the hypertension after renal transplant include preexisting hypertension, native kidney disease, medications like steroids, calcineurin inhibitors, both cold and warm ischemia times, graft dysfunction, renal artery stenosis, thrombotic microangiopathy, and postbiopsy arteriovenous fistula, The pathogenesis of the hypertension includes sodium and water retention, activation of RAAS, sympathetic overactivity, inhibition of atrial natriuretic peptide, imbalance in the synthesis and degradation of Nitric Oxide, endothelial dysfunction, and oxidative stress. In general, the hypertension induced by cyclosporine is more severe when compared to tacrolimus. Management of hypertension in this group of patients includes close monitoring of the drug levels of immunesuppressive medications like cyclosporine and tacrolimus and using least amount of medication or switching to another medication (like cyclosporine to tacrolimus or sirolimus) needed for graft survival. Monitoring for drug interactions and avoiding or minimizing medications can increase the serum levels of the immune-suppressive medications. Calcium-channel blockers decrease the vasoconstriction induced by the calcineurin inhibitors and are considered in the management of hypertension in these patients. However, care should be taken in monitoring the levels of cyclosporine and tacrolimus as some of the CСB like diltiazem, verapamil, and nicardipine are known to interfere with the drug metabolism. In addition, thiazide and loop diuretics, ACE inhibitors, and ARB are also used either alone or in combination with control resistant hypertension. ACE inhibitors and ARB because of their antiproteinuric and antierythrocytosis effect are particularly useful. However, they can cause decrease in GFR and cause anemia and potentiate hyperkalemia. These medications should be avoided in patients with decreased GFR secondary to graft dysfunction and also in patients with posttransplant renal artery stenosis. Minoxidil may be considered in patients with tacrolimus-induced alopecia [106-108]. 


\section{Conclusions}

Hypertensive crisis is an important pediatric emergency associated with significant morbidity and mortality. Early diagnosis, aggressive but careful management depending on specific etiologies, and long-term follow-up will help in decreasing some of this burden. Both basic and clinical research efforts to further delineate risk factors, pathophysiology, and epidemiology should be prioritized. Thus improved knowledge will contribute to better therapies. Dietary and lifestyle modifications do not seem as important as the implementation of guidelines and policies in changing the prognosis of hypertensive crisis.

\section{Abbreviations}

$\begin{array}{ll}\text { CRP: } & \text { C-reactive protein } \\ \text { IL: } & \text { Interleukin } \\ \text { IF: } & \text { Interferon } \\ \text { TNF: } & \text { Tumor necrotic factor } \\ \text { ICAM: } & \text { Intercellular adhesion molecule } \\ \text { VCAM: } & \text { Vascular cell adhesion molecule } \\ \text { GFR: } & \text { Glomerular filtration rate. }\end{array}$

\section{Conflict of Interests}

The authors declare that there is no conflict of interests.

\section{References}

[1] P. M. Kearney, M. Whelton, K. Reynolds, P. K. Whelton, and J. He, "Global burden of hypertension: analysis of worldwide data," The Lancet, vol. 365, no. 9455, pp. 217-223, 2005.

[2] J. M. Sorof, D. Lai, J. Turner, T. Poffenbarger, and R. J. Portman, "Overweight, ethnicity, and the prevalence of hypertension in school-aged children," Pediatrics, vol. 113, no. 3, part 1, pp. 475-482, 2004.

[3] R. Din-Dzietham, Y. Liu, M. V. Bielo, and F. Shamsa, "High blood pressure trends in children and adolescents in national surveys, 1963 to 2002," Circulation, vol. 116, no. 13, pp. 1488-1496, 2007.

[4] J. Sorof and S. Daniels, "Obesity hypertension in children: a problem of epidemic proportions," Hypertension, vol. 40, no. 4, pp. 441-447, 2002.

[5] C. Ogden and M. Carroll, "Prevalence of Obesity Among Children and Adolescents: United States, Trends 19631965 Through 2007-2008," 2010, http://www.cdc.gov/nchs/ data/hestat/obesity_child_07_08/obesity_child_07_08.htm

[6] B. Falkner and S. R. Daniels, "Summary of the fourth report on the diagnosis, evaluation, and treatment of high blood pressure in children and adolescents," Hypertension, vol. 44, no. 4, pp. 387-388, 2004.

[7] K. L. McNiece, T. S. Poffenbarger, J. L. Turner, K. D. Franco, J. M. Sorof, and R. J. Portman, "Prevalence of hypertension and pre-hypertension among adolescents," Journal of Pediatrics, vol. 150, no. 6, pp. 640-e1, 2007.

[8] D. W. Jones and J. E. Hall, "Seventh report of the joint national committee on prevention, detection, evaluation, and treatment of high blood pressure and evidence from new hypertension trials," Hypertension, vol. 43, no. 1, pp. 1-3, 2004.

[9] M. Aggarwal and I. A. Khan, "Hypertensive crisis: hypertensive emergencies and urgencies," Cardiology Clinics, vol. 24, no. 1, pp. 135-146, 2006.

[10] M. Litwin, A. Niemirska, J. Sladowska et al., "Left ventricular hypertrophy and arterial wall thickening in children with essential hypertension," Pediatric Nephrology, vol. 21, no. 6, pp. 811-819, 2006.

[11] M. Litwin, J. Trelewicz, Z. Wawer et al., "Intima-media thickness and arterial elasticity in hypertensive children: controlled study," Pediatric Nephrology, vol. 19, no. 7, pp. 767-774, 2004.

[12] N. Prasad, S. Gulati, R. K. Gupta, R. Kumar, K. Sharma, and R. K. Sharma, "Is reversible posterior leukoencephalopathy with severe hypertension completely reversible in all patients?" Pediatric Nephrology, vol. 18, no. 11, pp. 11611166, 2003.

[13] B. J. Foster, H. Ali, S. Mamber, R. C. Polomeno, and A. S. MacKie, "Prevalence and severity of hypertensive retinopathy in children," Clinical Pediatrics, vol. 48, no. 9, pp. 926-930, 2009.

[14] M. E. Leder Skalina, W. L. Annable, R. M. Kliegman, and A. A. Fanaroff, "Hypertensive retinopathy in the newborn infant," Journal of Pediatrics, vol. 103, no. 5, pp. 781-786, 1983.

[15] B. McCoy, M. King, D. Gill, and E. Twomey, "Childhood posterior reversible encephalopathy syndrome," European Journal of Paediatric Neurology, vol. 15, no. 2, pp. 91-94, 2011.

[16] K. Ishikura, Y. Hamasaki, T. Sakai et al., "Posterior reversible encephalopathy syndrome in children with kidney diseases," Pediatric Nephrology, vol. 27, no. 3, pp. 375-384, 2012.

[17] R. S. Trompeter, R. L. Smith, and R. D. Hoare, "Neurological complications of arterial hypertension," Archives of Disease in Childhood, vol. 57, no. 12, pp. 913-917, 1982.

[18] B. Zampaglione, C. Pascale, M. Marchisio, and P. CavalloPerin, "Hypertensive urgencies and emergencies: prevalence and clinical presentation," Hypertension, vol. 27, no. 1, pp. 144-147, 1996.

[19] J. E. Tisdale, M. B. Huang, and S. Borzak, "Risk factors for hypertensive crisis: importance of out-patient blood pressure control," Family Practice, vol. 21, no. 4, pp. 420-424, 2004.

[20] S. Shea, D. Misra, M. H. Ehrlich, L. Field, and C. K. Francis, "Predisposing factors for severe, uncontrolled hypertension in an inner-city minority population," The New England Journal of Medicine, vol. 327, no. 11, pp. 776-781, 1992.

[21] S. Shea, D. Misra, M. H. Ehrlich, L. Field, and C. K. Francis, "Correlates of nonadherence to hypertension treatment in an inner-city minority population," American Journal of Public Health, vol. 82, no. 12, pp. 1607-1612, 1992.

[22] Y. Ostchega, J. P. Hughes, J. D. Wright, M. A. McDowell, and T. Louis, "Are demographic characteristics, health care access and utilization, and comorbid conditions associated with hypertension among US adults?" American Journal of Hypertension, vol. 21, no. 2, pp. 159-165, 2008.

[23] J. E. Deal, T. M. Barratt, and M. J. Dillon, "Management of hypertensive emergencies," Archives of Disease in Childhood, vol. 67, no. 9, pp. 1089-1092, 1992. 
[24] M. Singh, G. A. Mensah, and G. Bakris, "Pathogenesis and clinical physiology of hypertension," Cardiology Clinics, vol. 28, no. 4, pp. 545-559, 2010.

[25] B. J. Sobel and L. B. George, Hypertension: A Clinician's Guide to Diagnosis and Treatment, Hanley and Belfus, Philadelphia, Pa, USA, 1999.

[26] H. P. Patel and M. Mitsnefes, "Advances in the pathogenesis and management of hypertensive crisis," Current Opinion in Pediatrics, vol. 17, no. 2, pp. 210-214, 2005.

[27] S. Oparil, M. A. Zaman, and D. A. Calhoun, "Pathogenesis of hypertension," Annals of Internal Medicine, vol. 139, no. 9, pp. 761-776, 2003.

[28] T. A. Kotchen and G. P. Guthrie Jr., "Renin-angiotensinaldosterone and hypertension," Endocrine Reviews, vol. 1, no. 1, pp. 78-99, 1980.

[29] G. P. Guthrie Jr., "Angiotensin receptors: physiology and pharmacology," Trends in Pharmacological Sciences, vol. 18, no. 6, supplement 3, pp. 29-34, 1995.

[30] A. K. Doughan, D. G. Harrison, and S. I. Dikalov, "Molecular mechanisms of angiotensin II-mediated mitochondrial dysfunction: linking mitochondrial oxidative damage and vascular endothelial dysfunction," Circulation Research, vol. 102, no. 4, pp. 488-496, 2008.

[31] W. Zhang, W. Wang, H. Yu et al., "Interleukin 6 underlies angiotensin II-induced hypertension and chronic renal damage," Hypertension, vol. 59, pp. 136-144, 2012.

[32] C. Cousin, D. Bracquart, A. Contrepas, and G. Nguyen, "Potential role of the (pro)renin receptor in cardiovascular and kidney diseases," Journal of Nephrology, vol. 23, no. 5, pp. 508-513, 2010.

[33] M. S. Madhur, H. E. Lob, L. A. McCann et al., "Interleukin 17 promotes angiotensin II-induced hypertension and vascular dysfunction," Hypertension, vol. 55, no. 2, pp. 500-507, 2010.

[34] P. Stenvinkel, M. Ketteler, R. J. Johnson et al., "IL-10, IL-6, and TNF- $\alpha$ : central factors in the altered cytokine network of uremia - the good, the bad, and the ugly," Kidney International, vol. 67, no. 4, pp. 1216-1233, 2005.

[35] B. Chamarthi, G. H. Williams, V. Ricchiuti et al., "Inflammation and hypertension: the interplay of interleukin-6, dietary sodium, and the renin-angiotensin system in humans," American Journal of Hypertension, vol. 24, no. 10, pp. 11431148, 2011.

[36] D. G. Harrison, T. J. Guzik, H. Lob et al., "Inflammation, immunity, and hypertension," Hypertension, vol. 57, no. 2, pp. 132-140, 2011.

[37] D. N. Muller, H. Kvakan, and F. C. Luft, "Immune-related effects in hypertension and target-organ damage," Current Opinion in Nephrology and Hypertension, vol. 20, no. 2, pp. 113-117, 2011.

[38] D. G. Harrison, T. J. Guzik, J. Goronzy, and C. Weyand, "Is hypertension an immunologic disease?" Current Cardiology Reports, vol. 10, no. 6, pp. 464-469, 2008.

[39] A. Papayianni, E. Alexopoulos, P. Giamalis et al., "Circulating levels of ICAM-1, VCAM-1, and MCP-1 are increased in haemodialysis patients: association with inflammation, dyslipidaemia, and vascular events," Nephrology Dialysis Transplantation, vol. 17, no. 3, pp. 435-441, 2002.

[40] C. A. Desouza, D. R. Dengel, R. F. Macko, K. Cox, and D. R. Seals, "Elevated levels of circulating cell adhesion molecules in uncomplicated essential hypertension," American Journal of Hypertension, vol. 10, no. 12, part 1, pp. 1335-1341, 1997.
[41] E. Y. Senchenkova, J. Russell, E. Kurmaeva, D. Ostanin, and D. N. Granger, "Role of T lymphocytes in angiotensin IImediated microvascular thrombosis," Hypertension, vol. 58, no. 5, pp. 959-965, 2011.

[42] H. Kvakan, F. C. Luft, and D. N. Muller, "Role of the immune system in hypertensive target organ damage," Trends in Cardiovascular Medicine, vol. 19, no. 7, pp. 242-246, 2009.

[43] E. Schulz, T. Gori, and T. Münzel, "Oxidative stress and endothelial dysfunction in hypertension," Hypertension Research, vol. 34, no. 6, pp. 665-6673, 2011.

[44] A. Virdis, E. Duranti, and S. Taddei, "Oxidative stress and vascular damage in hypertension: role of angiotensin II," International Journal of Hypertension, vol. 2011, Article ID 916310, 7 pages, 2011.

[45] R. Rodrigo, J. González, and F. Paoletto, "The role of oxidative stress in the pathophysiology of hypertension," Hypertension Research, vol. 34, no. 4, pp. 431-440, 2011.

[46] U. Förstermann and W. C. Sessa, "Nitric oxidesynthases: regulation and function," European Heart Journal. 2011 Sep. 1 , In press.

[47] H. Takahashi, M. Yoshika, Y. Komiyama, and M. Nishimura, "The central mechanism underlying hypertension: a review of the roles of sodium ions, epithelial sodium channels, the renin-angiotensin-aldosterone system,oxidative stress and endogenous digitalis in the brain," Hypertension Research, vol. 34, no. 11, pp. 1147-1160, 2011.

[48] M. G. Butler, "Genetics of hypertension," Journal Medical Libanais, vol. 58, no. 3, pp. 175-178, 2010.

[49] N. K. Lima, F. Abbasi, C. Lamendola, and G. M. Reaven, "Prevalence of insulin resistance and related risk factors for cardiovascular disease in patients with essential hypertension," American Journal of Hypertension, vol. 22, no. 1, pp. 106-111, 2009.

[50] M. P. Kelly, P. A. Quinn, J. E. Davies, and L. L. Ng, "Activity and expression of $\mathrm{Na}^{+}-\mathrm{H}^{+}$exchanger isoforms 1 and 3 in kidney proximal tubules of hypertensive rats," Circulation Research, vol. 80, no. 6, pp. 853-860, 1997.

[51] F. Lang, G. Capasso, M. Schwab, and S. Waldegger, "Renal tubular transportand the genetic basis of hypertensive disease," Clinical and Experimental Nephrology, vol. 9, no. 2, pp. 91-99, 2005.

[52] J. T. Flynn, "Neonatal hypertension: diagnosis and management," Pediatric Nephrology, vol. 14, no. 4, pp. 332-341, 2000.

[53] M. M. Mitsnefes, "Hypertension in children and adolescents," Pediatric Clinics of North America, vol. 53, no. 3, pp. 493-512, 2006.

[54] B. M. Chavers and C. A. Herzog, "The spectrum of cardiovascular disease in children with predialysis chronic kidney disease," Advances in Chronic Kidney Disease, vol. 11, no. 3, pp. 319-327, 2004.

[55] A. C. Wilson and M. M. Mitsnefes, "Cardiovascular disease in CKD in children: update on risk factors, risk assessment, and management," American Journal of Kidney Diseases, vol. 54, no. 2, pp. 345-360, 2009.

[56] P. R. Khoury, M. Mitsnefes, S. R. Daniels, and T. R. Kimball, "Age-specific reference intervals for indexed left ventricular mass in children," Journal of the American Society of Echocardiography, vol. 22, no. 6, pp. 709-714, 2009.

[57] C. Hanevold, J. Waller, S. Daniels, R. Portman, and J. Sorof, "The effects of obesity, gender, and ethnic group on left ventricular hypertrophy and geometry in hypertensive 
children: a collaborative study of the international pediatric hypertension association," Pediatrics, vol. 113, no. 2, pp. 328333, 2004.

[58] P. W. de Leeuw and A. A. Kroon, "Hypertension and the development of heart failure," Journal of Cardiovascular Pharmacology, vol. 32, supplement 1, pp. S9-S15, 1998.

[59] J. Imperato-McGinley, T. Gautier, K. Ehlers, M. A. Zullo, D. S. Goldstein, and E. D. Vaughan Jr., "Reversibility of catecholamine-induced dilated cardiomyopathy in a child with a pheochromocytoma," The New England Journal of Medicine, vol. 316, no. 13, pp. 793-797, 1987.

[60] K. C. Hawkins, A. R. Watson, and N. Rutter, "Neonatal hypertension and cardiac failure," European Journal of Pediatrics, vol. 154, no. 2, pp. 148-149, 1995.

[61] C. Lamotte, C. Iliescu, C. Libersa, and F. Gottrand, "Increased intima-media thickness of the carotid artery in childhood: a systematic review of observational studies," European Journal of Pediatrics, vol. 170, no. 6, pp. 719-729, 2010.

[62] O. Elkiran, E. Yilmaz, M. Koc, A. Kamanli, B. Ustundag, and N. Ilhan, "The association betweenintima media thickness, central obesity and diastolic blood pressure in obese and owerweight children: a cross-sectional school-based study," International Journal of Cardiology. 2011 Oct. 17, In press.

[63] M. B. Lande, N. L. Carson, J. Roy, and C. C. Meagher, "Effects of childhood primary hypertension on carotid intima media thickness: a matched controlled study," Hypertension, vol. 48, no. 1, pp. 40-44, 2006.

[64] R. V. Immink, B. J. H. Van Den Born, G. A. Van Montfrans, R. P. Koopmans, J. M. Karemaker, and J. J. Van Lieshout, "Impaired cerebral autoregulation in patients with malignant hypertension," Circulation, vol. 110, no. 15, pp. 2241-2245, 2004.

[65] R. R. Wright and K. D. Mathews, "Hypertensive encephalopathy in childhood," Journal of Child Neurology, vol. 11, no. 3, pp. 193-196, 1996.

[66] M. H. Yang, J. N. Sheu, and S. J. Wang, "Cortical blindness in a boy with acute glomerulonephritis," Journal of the Formosan Medical Association, vol. 102, no. 1, pp. 52-54, 2003.

[67] D. Taylor, J. Ramsay, S. Day, and M. Dillon, "Infarction of the optic nerve head in children with accelerated hypertension," British Journal of Ophthalmology, vol. 65, no. 3, pp. 153-160, 1981.

[68] J. A. Hulse, D. S. Taylor, and M. J. Dillon, "Blindness and paraplegia in severe childhood hypertension," The Lancet, vol. 2, no. 8142, pp. 553-556, 1979.

[69] A. C. Browning, L. S. Mengher, R. M. Gregson, and W. M. Amoaku, "Visual outcome of malignant hypertension in young people," Archives of Disease in Childhood, vol. 85, no. 5, pp. 401-403, 2001.

[70] R. S. Kandt, A. Q. Caoili, W. B. Lorentz, and A. D. Elster, "Hypertensive encephalopathy in children: neuroimaging and treatment," Journal of Child Neurology, vol. 10, no. 3, pp. 236-239, 1995.

[71] A. Kahana, H. A. Rowley, and J. M. Weinstein, "Cortical blindness: clinical and radiologic findings in reversible posterior leukoencephalopathy syndrome-case report and review of the literature," Ophthalmology, vol. 112, no. 2, pp. e7-e11, 2005.
[72] C. J. Gardner and K. Lee, "Hyperperfusion syndromes: insight into the pathophysiology and treatment of hypertensive encephalopathy," CNS Spectrums, vol. 12, no. 1, pp. 3542, 2007.

[73] L. Shavit, C. Reinus, and I. Slotki, "Severe renal failure and microangiopathic hemolysis induced by malignant hypertension-case series and review of literature," Clinical Nephrology, vol. 73, no. 2, pp. 147-152, 2010.

[74] Y. Otsuka, K. Abe, and Y. Sato, "Malignant hypertension and microangiopathic hemolytic anemia," Japanese Heart Journal, vol. 17, no. 2, pp. 258-264, 1976.

[75] R. Lubrano, E. Travasso, C. Raggi, G. Guido, R. Masciangelo, and M. Elli, "Blood pressure load, proteinuria and renal function in pre-hypertensive children," Pediatric Nephrology, vol. 24, no. 4, pp. 823-831, 2009.

[76] F. Assadi, "Effect of microalbuminuria lowering on regression of left ventricular hypertrophy in children and adolescents with essential hypertension," Pediatric Cardiology, vol. 28, no. 1, pp. 27-33, 2007.

[77] P. Logan, P. Eustace, and R. Robinson, "Hypertensive retinopathy: a cause of decreased visual acuity in children," Journal of Pediatric Ophthalmology \& Strabismus, vol. 29, no. 5, pp. 287-289, 1992.

[78] R. E. Meetz and T. A. Harris, "The optometrist's role in the management of hypertensive crises," Optometry, vol. 82, no. 2, pp. 108-116, 2011.

[79] J. B. Walsh, "Hypertensive retinopathy. Description, classification, and prognosis," Ophthalmology, vol. 89, no. 10, pp. 1127-1131, 1982.

[80] T. Y. Wong and P. N. Mitchell, "Hypertensive retinopathy," The New England Journal of Medicine, vol. 351, no. 22, pp. 2310-2317, 2004.

[81] S. R. Daniels, M. J. Lipman, M. J. Burke, and J. M. H. Loggie, "The prevalence of retinal vascular abnormalities in children and adolescents with essential hypertension," American Journal of Ophthalmology, vol. 111, no. 2, pp. 205208, 1991.

[82] F. Amraoui, G. A. van Montfrans, and B. J. H. van den Born, "Value of retinal examination in hypertensive encephalopathy," Journal of Human Hypertension, vol. 24, no. 4, pp. 274279, 2010.

[83] J. T. DellaCroce and A. T. Vitale, "Hypertension and the eye," Current Opinion in Ophthalmology, vol. 19, no. 6, pp. 493498, 2008.

[84] M. I. Perez and V. M. Musini, "Pharmacological interventions for hypertensive emergencies," Cochrane Database of Systematic Reviews, vol. 19, no. 6, pp. 493-498, 2008.

[85] K. Heard, R. Palmer, and N. R. Zahniser, "Mechanisms of acute cocaine toxicity," The Open Pharmacology Journal, vol. 2, no. 9, pp. 70-78, 2008.

[86] L. R. Goldfrank and R. S. Hoffman, "The cardiovascular effects of cocaine," Annals of Emergency Medicine, vol. 20, no. 2, pp. 165-175, 1991.

[87] M. Shannon, P. G. Lacouture, J. Roa, and A. Woolf, "Cocaine exposure among children seen at a pediatric hospital," Pediatrics, vol. 83, no. 3, pp. 337-342, 1989.

[88] M. Thorp, D. Toombs, and B. Harmon, "Monoamine oxidase inhibitor overdose," Western Journal of Medicine, vol. 166, no. 4, pp. 275-277, 1997. 
[89] D. G. Wells and A. R. Bjorksten, "Monoamine oxidase inhibitors revisited," Canadian Journal of Anaesthesia, vol. 36, no. 1, pp. 64-74, 1989.

[90] H. C. Bethune, R. H. Burrell, R. H. Culpan, and G. J. Ogg, "Vascular crises associated with monoamine-oxidase inhibitors," The American Journal of Psychiatry, vol. 121, no. 3, pp. 245-248, 1964.

[91] E. Ciocatto, G. Fagiano, and G. L. Bava, "Clinical features and treatment of overdosage of monoamine oxidase inhibitors and their interaction with other psychotropic drugs," Resuscitation, vol. 1, no. 1, pp. 69-72, 1972.

[92] S. R. White, "Amphetamine toxicity," Seminars in Respiratory and Critical Care Medicine, vol. 23, no. 1, pp. 27-36, 2002.

[93] G. Smets, K. Bronselaer, K. De Munnynck, K. De Feyter, W. Van de Voorde, and M. Sabbe, "Amphetamine toxicity in the emergency department," European Journal of Emergency Medicine, vol. 12, no. 4, pp. 193-197, 2005.

[94] S. M. Zuber, V. Kantorovich, and K. Pacak, "Hypertension in pheochromocytoma: characteristics and treatment," Endocrinology \& Metabolism Clinics of North America, vol. 40, no. 2, pp. 295-311, 2011.

[95] A. D. Ludwig, D. I. Feig, M. L. Brandt, M. J. Hicks, M. E. Fitch, and D. L. Cass, "Recent advances in the diagnosis and treatment of pheochromocytoma in children," American Journal of Surgery, vol. 194, no. 6, pp. 792-797, 2007.

[96] B. Havekes, J. A. Romijn, G. Eisenhofer, K. Adams, and K. Pacak, "Update on pediatric pheochromocytoma," Pediatric Nephrology, vol. 24, no. 5, pp. 943-950, 2009.

[97] P. Laje and P. A. Mattei, "Laparoscopic adrenalectomy for adrenal tumors in children: a case series," Journal of Laparoendoscopic and Advanced Surgical Techniques, vol. 19, no. 1, supplement, pp. S27-S29, 2009.

[98] K. Tullus, E. Brennan, G. Hamilton et al., "Renovascular hypertension in children," The Lancet, vol. 371, no. 9622, pp. 1453-1463, 2008.

[99] M. Kanitkar, "Renovascular hypertension," Indian Pediatrics, vol. 42, no. 1, pp. 47-54, 2005.

[100] F. Schaefer, "Hypertension in chronic kidney disease," in Clinical Hypertension and Vacular Diseases: Pediatric Hypertension, J. T. Flynn, J. R. Ingelfinger, and R. J. Portman, Eds., Springer, LLC, 2011.

[101] W. H. Hörl, "Hypertension in end-stage renal disease: different measures and their prognostic significance," Nephrology Dialysis Transplantation, vol. 25, no. 10, pp. 3161-3166, 2010.

[102] K. Benz and K. Amann, "Thrombotic microangiopathy: new insights," Current Opinion in Nephrology and Hypertension, vol. 19, no. 3, pp. 242-247, 2010.

[103] S. Johnson and C. M. Taylor, "Hemolytic uremic syndrome," in Pediatric Nephrology, E. D. Avner and D. Ellis, Eds., Springer, 6th edition, 2009.

[104] J. Scheiring, S. P. Andreoli, and L. B. Zimmerhackl, "Treatment and outcome of Shiga-toxin-associated hemolytic uremic syndrome (HUS)," Pediatric Nephrology, vol. 23, no. 10, pp. 1749-1760, 2008.

[105] O. Boyer and P. Niaudet, "Hemolytic uremic syndrome: new developments in pathogenesis and treatment," International Journal of Nephrology, vol. 2011, Article ID 908407, 10 pages, 2011.

[106] M. Mangray and J. P. Vella, "Hypertension after kidney transplant," American Journal of Kidney Diseases, vol. 57, no. 2, pp. 331-341, 2011.
[107] C. Ponticelli, D. Cucchiari, and G. Graziani, "Hypertension in kidney transplant recipients," Transplant International, vol. 24, no. 6, pp. 523-533, 2011.

[108] T. Seeman, "Hypertension after renal transplantation," Pediatric Nephrology, vol. 24, no. 5, pp. 959-972, 2009. 


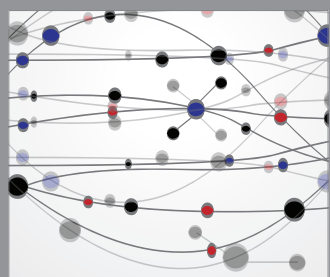

The Scientific World Journal
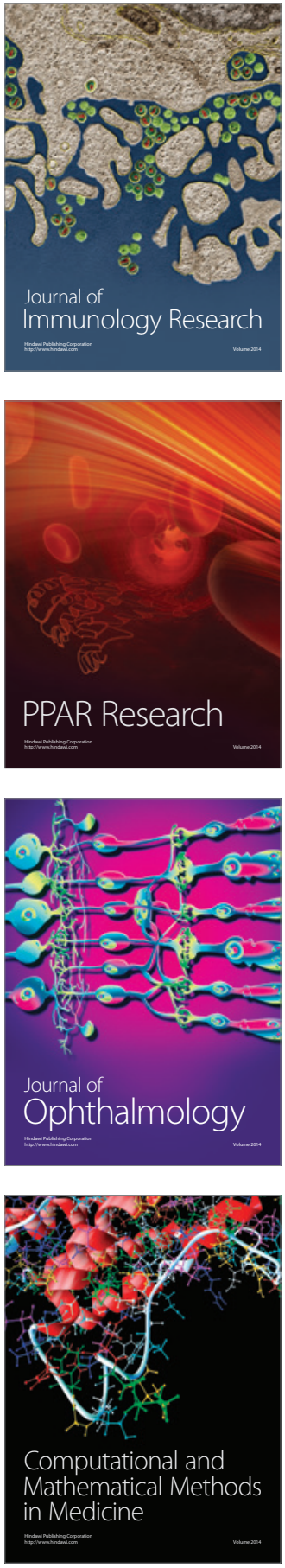

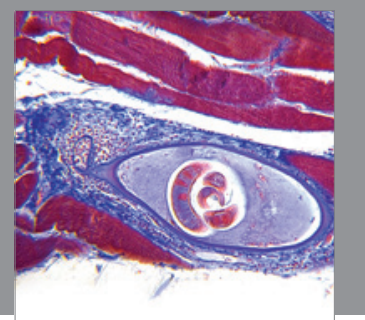

Gastroenterology

Research and Practice
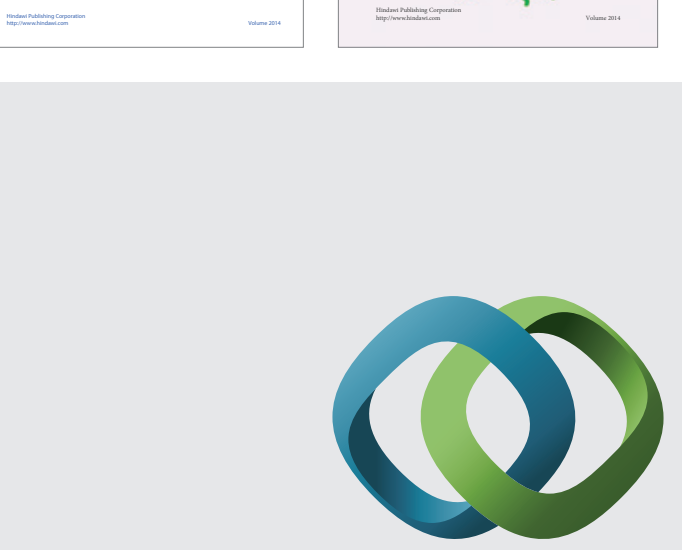

\section{Hindawi}

Submit your manuscripts at

http://www.hindawi.com
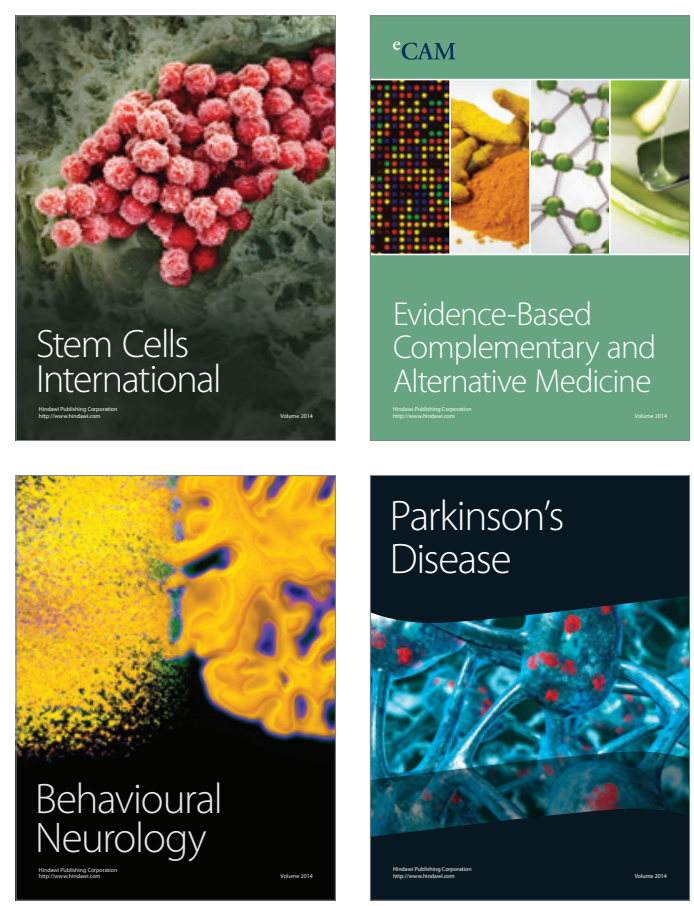

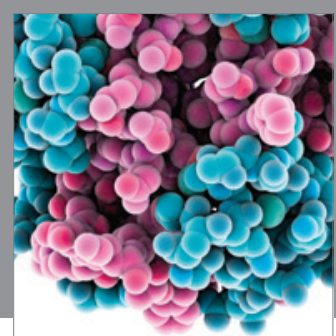

Journal of
Diabetes Research

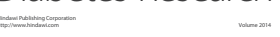

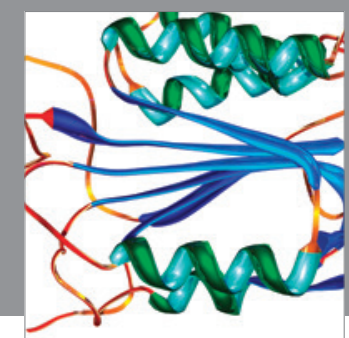

Disease Markers
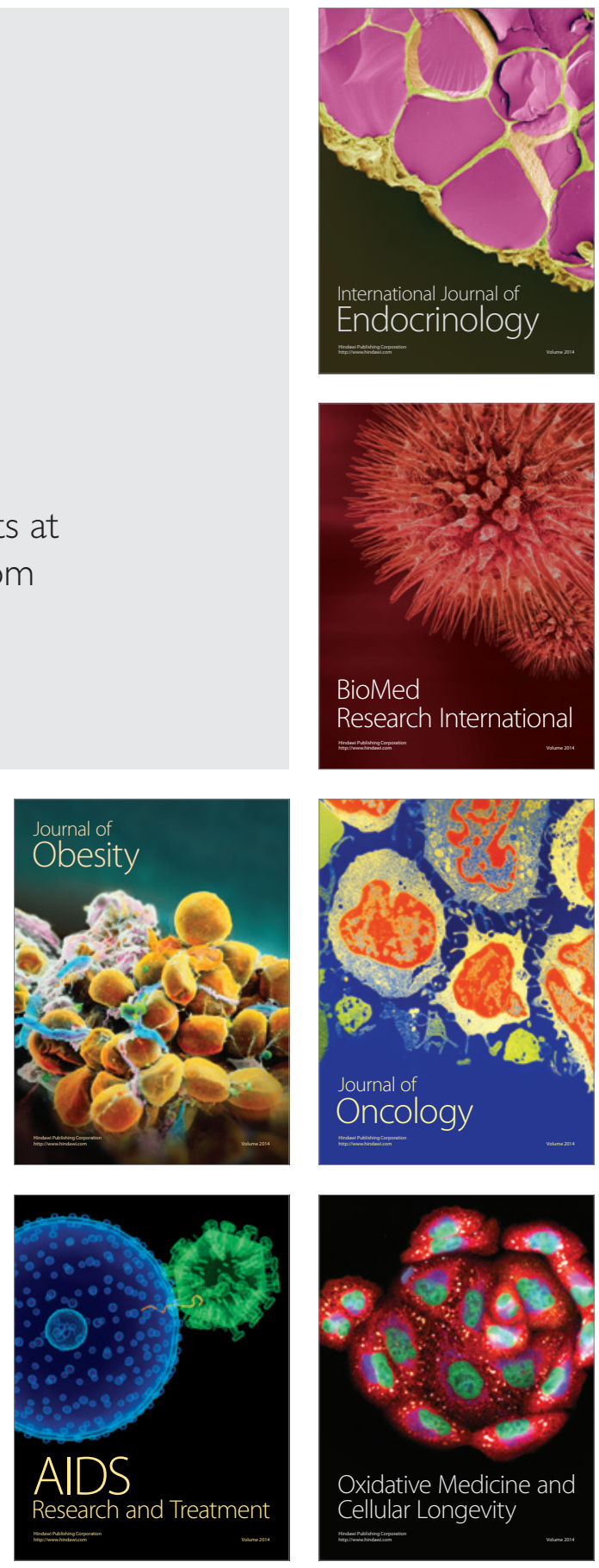